\title{
Self-induced myocardial infarction
}

\author{
Peter CARr \\ B.M., M.R.C.P. \\ Department of Medicine, Manchester Royal Infirmary, Oxford Road, Manchester M13 9WL
}

\begin{abstract}
Summary
A case of acute myocardial infarction and peripheral vascular insufficiency following overdose with ergotamine is described.

\section{Introduction}

Despite the prevalence of migraine and the widespread use of ergotamine preparations in its treatment, there are few reports of the effect of a massive overdose of these compounds. This case illustrates the consequences of an overdose of Migril, a compound containing 2 mg ergotamine tartrate B.P., $50 \mathrm{mg}$ cyclizine hydrochloride B.P. and $100 \mathrm{mg}$ caffeine hydrate B.P. per tablet.
\end{abstract}

\section{Case report}

A 29-year-old man was admitted as an emergency after taking 60 Migril tablets. A migraine sufferer for several years, he had a past history of attempted suicide, but otherwise had been well. There was no family history of heart disease.

On physical examination he was obese and had old scars on the wrists from a previous attempted suicide. The apex rate was 160 beats/min, BP $130 / 70 \mathrm{mmHg}$, heart sounds, peripheral pulses and skin circulation were normal. There was no abnormality in the chest, abdomen or nervous system.

On admission, the serum urea and electrolytes were normal. An electrocardiogram showed atrial fibrillation which reverted spontaneously to sinus rhythm with a normal record.

Gastric lavage was not performed because the patient had been vomiting. He remained well until $16 \mathrm{hr}$ after admission when he had a series of cardiac arrests (ECG showed both ventricular fibrillation and asystole), and aspirated vomit. He was resuscitated but remained hypotensive for several hours and developed transient oliguria with azotaemia (serum urea $24 \mathrm{mmol} / \mathrm{l}$ ). He also developed pneumonia.

During the second day of the admission the peripheral pulses became impalpable, the toes of the left foot becoming gangrenous and anaesthetic. Left femoral angiography confirmed arterial spasm in tae popliteal artery. Serial electrocardiographs showe the changes of an acute infero-lateral myocardig infarction.

Treatment with i.v. sodium nitroprusside 8 $200 \mu \mathrm{g} / \mathrm{min}$, and hydroxocobalamin was started of the third day and the peripheral pulses becange palpable again within $30 \mathrm{~min}$. The infusion was continued for 5 days until withdrawal was nơt followed by signs of vasoconstriction. He made good progress and the pneumonia and renal failure resolved completely. There was sloughing of the sk at the tip of the toes of the left foot only. Three months later the changes in the electrocardiogoa $\bar{B}$ were still present.

\section{Discussion}

The sequelae of this patient's overdose are thoug to be related directly to ergotamine, although it $\bar{S}$ possible that the transient atrial fibrillation w related to the caffeine ingestion (Goodman anA Gilman, 1980). The patient ingested $120 \mathrm{mg} \overrightarrow{\theta f}$ ergotamine tartrate; the maximum recommended dose is $4 \mathrm{mg} /$ day, and $12 \mathrm{mg}$ in one week.

Myocardial ischaemia has been described after. the administration of conventional doses of erget derivatives in migrainous subjects with and witho heart disease (Snell, Russell-Smith and Coys 1978), but myocardial infarction has been reportend rarely (Goldfischer, 1960; Fuchs and Blumentha, 1950). Ischaemia of the extremities due to ergot alkaloids is well recognized and historically is know as St Antony's Fire.

Sodium nitroprusside is the treatment of choice for ergotamine poisoning, and should be given with hydroxocobalamin. Its use is influenced by impaired renal function (Leading Article, 1978). In this caș it was commenced after the development of gangrew ous change, and when renal function was improving. In retrospect it may be argued that its prompt use after the patient's admission may have avoided ardy untoward complications. It is certain that it pre vented more extensive peripheral ischaemia and possibly further myocardial damage. 


\section{References}

Fuchs, M. \& Blumenthal, L. (1950) Use of ergot preparations in migraine. Journal of the American Medical Association, 43, 1462.

GOLDFISCHER, J.D. (1960) Acute myocardial infarction secondary to ergot therapy. New England Journal of Medicine, 262, 860.

Goodman, L.S. \& Gilman, A. (1980) The Pharmacological
Basis of Therapeutics, 6th Edn, p. 595. Macmillan Publishing Company, New York.

LeAding Article (1978) Controlled intravascular sodium nitroprusside treatment. British Medical Journal, 2, 784.

Snell, N.J.C., Russell-Smith, C. \& Coysh, H.L. (1978) Myocardial ischaemia in migraine sufferers taking ergotamine. Postgraduate Medical Journal, 54, 37. 